DOI https://doi.org/10.30525/978-9934-588-81-5-1.22

\title{
ВЛИЯНИЕ ТЕРАПИИ ИНГАЛЯЦИОННЫМИ ГЛЮКОКОРТИКОСТЕРОИДАМИ НА КОНЦЕНТРАЦИЮ ОКСИДА АЗОТА В ВЫДЫХАЕМОМ ВОЗДУХЕ У БОЛЬНЫХ ХРОНИЧЕСКИМ ОБСТРУКТИВНЫМ ЗАБОЛЕВАНИЕМ ЛЕГКИХ
}

\author{
Ефимова Н. А. \\ кандидат медицинских наук, \\ ассистент кафедры семейной медицины \\ факультета последипломного образования \\ Днепропетровская медицинская академия \\ Министерства здравоохранения Украины \\ г. Днепр, Украина
}

Хроническое обструктивное заболевание легких (ХОЗЛ) - прогрессирующее хроническое заболевание легких, характеризующееся стойкой бронхиальной обструкцией [1] и хроническим воспалением дыхательных путей, лежащее в основе патогенеза заболевания [2]. В настоящее время подходы к назначению ингаляционных глюкокортикостероидов (ИГКС) при ХОЗЛ претерпевают существенные изменения [3]. По данным многочисленных исследований доказано, что при применении ИГКС у больных ХОЗЛ замедляется прогрессирование заболевания и улучшается прогноз [4]. Вместе с тем, в литературе отмечена неоднозначность данных, показывающих влияние ИГКС на уровень фракции оксида азота (NO) в выдыхаемом воздухе, который является одним из воспалительных биомаркеров, что и определило цель нашего исследования.

Цель: изучить изменение концентрации NO в выдыхаемом воздухе под воздействием ИГКС у больных ХОЗЛ III и IV стадий в фазе ремиссии.

Материалы и методы:

Было обследовано 29 мужчин, страдающих ХОЗЛ III и IV стадий в фазе ремиссии. Средний возраст пациентов составил 58,67 $\pm 1,37$ лет, средняя длительность заболевания $-7,47 \pm 0,35$ лет. В группу I вошли пациенты принимающие в составе базисной терапии ИГКС - 15 человек, в группу II - пациенты, которые либо отказывались от постоянного приема ИГКС, либо принимали ИГКС не регулярно - 14 человек. 
Функция внешнего дыхания определялась при помощи спирографа MasterLab (Jeger, Германия); концентрация NO в выдыхаемом воздухе - аппаратом Niox Mino (Aerocrine, Швеция). Обе группы были сопоставимы по возрасту, длительности заболевания и функции внешнего дыхания.

Результаты:

В результате исследования было установлено, что в группе I концентрация выдыхаемого NO была достоверно ниже, чем в группе II $(11,69 \pm 2,24 \mathrm{ppb}$ и $15,11 \pm 1,81 \mathrm{ppb}$ соответственно $(\mathrm{p}<0,05))$. В I и II группах уровень NO в выдыхаемом воздухе достоверно коррелировал с длительностью заболевания $(\mathrm{r}=0,24, \mathrm{p}=0,041 ; \mathrm{r}=0,43$, $\mathrm{p}=0,032)$. При оценке влияния возраста на уровень NO в выдыхаемом воздухе выявлено, что уровень $\mathrm{NO}$ достоверно коррелировал с возрастом пациентов в группе II $(\mathrm{r}=0,46, \mathrm{p}=0,048)$. В исследуемых группах не было обнаружено достоверной связи между уровнем NO и функцией внешнего дыхания.

Выводы:

1) использование ИГКС приводит к снижению уровня выдыхаемого NO у больных ХОЗЛ III и IV стадий в фазе ремиссии, что может угнетать активность воспалительного процесса и уменьшать бронхообструктивные нарушения;

2) концентрация выдыхаемого NO увеличивается с длительностью заболевания у больных при стабильном течении XОЗЛ III и IV стадий, что может быть ассоциировано с прогрессированием воспалительного процесса и бронхообструктивных проявлений;

3) уровень выдыхаемого NO не повышается с возрастом у больных ХОЗЛ, которые принимают в составе базисной терапии ИГКС, что может свидетельствовать о снижении темпов прогрессирования заболевания у пациентов регулярно принимающих ИГКС;

4) уровень выдыхаемого NO повышается с возрастом у больных, которые не принимают ИГКС при ХОЗЛ III и IV стадий в фазе ремиссии, что может свидетельствовать о прогрессировании заболевания;

5) уровень NO в выдыхаемом воздухе не коррелирует с показателями функции внешнего дыхания у больных ХОЗЛ III и IV стадий в фазе ремиссии.

\section{Литература:}

1. Global Initiative for Chronic Obstructive Lung Disease.Global Strategy for Prevention, Diagnosis and Management of COPD. 2019 
GOLD Reports. Available at: https://goldcopd.org/gold-reports/ (Accessed: December 11, 2018).

2. Barnes P.J. Cellular and molecular mechanisms of chronic obstructive pulmonary disease. Clin. Chest Med. 2014; 35 (1): 71-86. DOI: $10.1016 /$ j.ccm.2013.10.004.

3. Cataldo D., Derom E., Liistro G. et al. Overuse of inhaled corticosteroids in COPD: five questions for withdrawal in daily practice. Int. J. Chron. Obstruct. Pulmon. Dis. 2018; 13: 2089-2099. DOI: $10.2147 /$ COPD.S164259.

4. Gershon A.S., Campitelli M.A., Croxford R. et al. Combination long-acting $\beta$-agonists and inhaled corticosteroids compared with long-acting $\beta$-agonists alone in older adults with chronic obstructive pulmonary disease. JAMA. 2014; 312 (11): 1114-1121. DOI: 10.1001/jama.2014.11432.

DOI https://doi.org/10.30525/978-9934-588-81-5-1.23

\title{
ОСОБЛИВОСТІ КЛІНІЧНОЇ КАРТИНИ ХВОРИХ ІЗ ПРОСТАТИЧНОЮ ІНТРАЕПІТЕЛІАЛЬНОЮ НЕОПЛАЗІЕЮ
}

\author{
Зайцев В. I. \\ кандидат медичних наук, професор, \\ професор кафедри урології та нейрохірургії \\ ВДНЗ «Буковинський державний медичний університет» \\ Ілюк I. I. \\ кандидат медичних наук, доиент, \\ доиент кафедри урології та нейрохірургії \\ ВДНЗ «Буковинський державний медичний університет» \\ Марчук О. А. \\ лікар-інтерн уролог, \\ кафедра урології та нейрохірургії \\ ВДНЗ «Буковинський державний медичний університет» \\ м. Чернівиі, Україна
}

Актуальність. На сьогоднішній день, виявлення раку простати на ранній стадії залишається актуальною проблемою в усьому світі. На жаль основні методи діагностики РП, такі як: пальцеве ректальне 